\title{
Novel Schizophrenia Risk Gene TCF4 Influences Verbal Learning and Memory Functioning in Schizophrenia Patients
}

\author{
Leonhard Lennertz $^{\mathrm{a}}$ Dan Rujescu ${ }^{\mathrm{b}}$ Michael Wagner ${ }^{\mathrm{a}}$ Ingo Frommann ${ }^{\mathrm{a}}$ \\ Svenja Schulze-Rauschenbach ${ }^{a}$ Anna Schuhmacher ${ }^{a}$ Martin W. Landsberg ${ }^{a}$ \\ Petra Franke ${ }^{c}$ Hans-Jürgen Möller ${ }^{b}$ Wolfgang Wölwer ${ }^{c}$ Wolfgang Gaebel ${ }^{c}$ \\ Heinz Häfner ${ }^{d}$ Wolfgang Maier ${ }^{a}$ Rainald Mössner ${ }^{a}$ \\ a Department of Psychiatry and Psychotherapy, University of Bonn, Bonn, ${ }^{\mathrm{b}}$ Department of Psychiatry and \\ Psychotherapy, University of Munich, Munich, ' Department of Psychiatry and Psychotherapy, University of \\ Düsseldorf, Düsseldorf, and ${ }^{\mathrm{d} C e n t r a l}$ Institute of Mental Health, Mannheim, Germany
}

\section{Key Words}

TCF4 $\cdot$ Schizophrenia $\cdot$ Verbal learning $\cdot$ Memory

\begin{abstract}
Background: Recently, a role of the transcription factor 4 (TCF4) gene in schizophrenia has been reported in a large genome-wide association study. It has been hypothesized that TCF4 affects normal brain development and TCF4 has been related to different forms of neurodevelopmental disorders. Schizophrenia patients exhibit strong impairments of verbal declarative memory (VDM) functions. Thus, we hypothesized that the disease-associated $C$ allele of the rs9960767 polymorphism of the TCF4 gene led to impaired VDM functioning in schizophrenia patients. Method: The TCF4 variant was genotyped in 401 schizophrenia patients. VDM functioning was measured using the Rey Auditory Verbal Learning Test (RAVLT). Results: Carriers of the $C$ allele were less impaired in recognition compared to those carrying the AA genotype (13.76 vs. 13.06; $p=0.049$ ). Moreover, a trend toward higher scores in patients with the risk allele was found for delayed recall (10.24 vs. 9.41; $p=0.088)$. The TCF4 genotype did not influence intelligence or RAVLT im-
\end{abstract}

mediate recall or total verbal learning. Conclusion: VDM function is influenced by the TCF4 gene in schizophrenia patients. However, the elevated risk for schizophrenia is not conferred by TCF4-mediated VDM impairment.

Copyright $\odot 2011$ S. Karger AG, Basel

\section{Introduction}

Schizophrenia is a severe and disabling disorder which belongs to the most burdensome and costly illnesses worldwide [1]. The disorder is characterized by several disturbances in affect, cognition and behavior. Family studies and twin studies investigating the heritability of schizophrenia substantiate a high genetic liability of schizophrenia which is estimated to explain up to $85 \%$ of the variance [2].

Due to the waning and waxing course of the disorder, it has been emphasized to regard the underlying neurobiological core features instead of the observable phenotype. These intermediate phenotypes, or endophenotypes, are assumed to mediate genetic and phenotypic variation $[3,4]$. Neurocognitive features have proven

\section{KARGER}

Fax +41613061234 E-Mail karger@karger.ch www.karger.com
(C) 2011 S. Karger AG, Basel

0302-282X/11/0633-0131\$38.00/0

Accessible online at:

www.karger.com/nps
PD Dr. Rainald Mössner, MD

Department of Psychiatry and Psychotherapy, University of Bonn

Sigmund-Freud-Strasse 25, DE-53105 Bonn (Germany)

Tel. +49 228287 19399, Fax +49 22828722617

E-Mail rainald.moessner@ukb.uni-bonn.de 
highly promising endophenotypes in schizophrenia research [5]. Among others, deficits in verbal declarative memory (VDM) have been investigated extensively, yielding standardized effect sizes up to 1.41 (Cohen's d) [6]. Thus, patients suffering from schizophrenia show marked deficits in verbal learning, retrieval and recognition [7]. Faraone et al. [8] demonstrated the cosegregation of verbal memory and schizophrenia liability. In their analyses, subjects with two or more affected family members (multiplex families) showed worse memory functioning than subjects with only one affected family member (simplex families) and healthy control subjects. In unaffected relatives, VDM deficits up to $\mathrm{d}=0.65$ were obtained, compared to healthy control subjects [9-11].

Recently, a large genome-wide association study (GWAS) was performed, reporting a novel genetic variant conferring a risk for schizophrenia [12]. This variant is located within intron 3 of transcription factor 4 (TCF4). The $\mathrm{C}$ allele of the rs 9960767 polymorphism was found to be more frequent in patients with schizophrenia, leading to a 1.23-fold higher risk for the disorder. The TCF4 gene is located on chromosome 18q21.2. In their genome scan metaanalysis of linkage studies on schizophrenia, Lewis et al. [13] found the 18q21.1-qter 'bin' ranked around fifteenth in the genome. The TCF4 gene is involved in normal brain development [14] and has been associated with the Pitt-Hopkins syndrome, a severe encephalopathy with autonomic dysfunctions like intermittent hyperventilation [15-18]. Recently, Kalscheuer et al. [19] reported a de novo translocation disrupting exon 4 of TCF 4 in a girl with mental retardation, thus suggesting that there are also milder phenotypic expressions of TCF4 variability compared to the Pitt-Hopkins syndrome.

Since VDM impairments have been related to abnormal hippocampal and prefrontal volume and activation in both schizophrenia patients and unaffected relatives $[20,21]$, we hypothesized that the TCF4 gene may influence neurodevelopment and thus alters VDM functioning. Following previous results of a recent GWAS, we tested for an association of the risk-conferring $\mathrm{C}$ allele of the rs9960767 polymorphism with impaired VDM functioning in schizophrenia patients.

\section{Patients and Method}

\section{Sample}

For the present investigation, we assessed 401 patients suffering from schizophrenia. All participants had given their written informed consent prior to inclusion. The patients were recruited in the Departments of Psychiatry of the Universities of Bonn, Cologne, Düsseldorf, Mannheim, Berlin, Tübingen, Jena and $\mathrm{Mu}-$ nich. Diagnoses were established according to criteria of the DSM-IV or ICD-10 [22, 23]. Subjects were excluded when diagnosed with any neurological disorder. Blood samples were collected and stored in the molecular genetics laboratories at the departments of psychiatry and psychotherapy of the universities of Bonn and Munich for genotyping.

Measures

VDM was assessed by the Rey Auditory Verbal Learning Test (RAVLT; Germantranslation: VerbalerLern-undMerkfähigkeitstest) [24]. The RAVLT is a highly reliable and valid test for VDM. Subjects are asked to learn a list (list A) of 15 words over 5 trials. After that, a second list (list B), consisting of 15 new words which have to be learned, is presented. Immediately after this interference list and again after $30 \mathrm{~min}$, free recall of list $\mathrm{A}$ is assessed (delayed recall). Recognition is measured by words read aloud. The test person is asked to categorize these words as belonging to list A, list B or a new list never presented. The RAVLT provides a number of different measures of VDM, all of which generally indicate impairments in schizophrenia patients. In order to restrict analyses and to reduce the probability of false-positive results due to $\alpha$ error accumulation, we selected 4 dependent variables: (1) recalled items from the first learning trial (short-term memory); (2) the sum of recalled items over the 5 learning trials (total learning); (3) delayed recall after $30 \mathrm{~min}$ (delayed recall), and (4) the sum of correctly recognized items of list A (recognition).

In 198 schizophrenia patients, verbal intelligence was estimated based on the score in a German vocabulary test, the Mehrfachwahl-Wortschatz-Test (MWT-B) [25]. In the remaining 203 schizophrenia cases, the German translation of the Wechsler Adult Intelligence Scale-Revised (WAIS-R) was used to measure intelligence [26].

\section{Genotyping}

DNA for single-nucleotide polymorphism (SNP) genotyping was isolated from EDTA anticoagulated blood using the Qiagen protocol for the Blood \& Cell Culture DNA Maxi Kit (Qiagen, Hilden, Germany). PCR was performed using $12.5 \mathrm{ng}$ of DNA, the Taqman $^{\circledR}$ Universal PCR MasterMix, No AmpErase ${ }^{\circledR}$ UNG and Taqman SNP Genotyping Assays for the SNP (all provided by Applied Biosystems, Foster City, Calif., USA) according to the protocol for Taqman SNP genotyping (Applied Biosystems). Each assay consisted of the unlabeled forward and reverse primers and the FAM- and VIC-dye-labeled MGB probes. Those assays are designed for allelic discrimination of specific SNP. Both alleles were scored in a single well by measuring the fluorescence at the end of the PCR, using a Tecan Ultra 384 reader (Tecan, Crailsheim, Germany). The excitation and emission wavelengths for the FAMlabeled probes were 485 and $535 \mathrm{~nm}$, and for the VIC-labeled probes, 535 and $590 \mathrm{~nm}$, respectively.

\section{Statistics}

All analyses were carried out at a significance level of $\mathrm{p}=0.05$. In order to eliminate center effects, RAVLT data were standardized using $\mathrm{z}$-transformation (mean $=0 ; \mathrm{SD}=1$ ). Similarly, MWT$\mathrm{B}$ and WAIS-R data were standardized and $\mathrm{Z}$ scores aggregated into 1 variable. VDM performance differences were assessed us- 
ing ANOVA with standardized VDM variables as dependent variables, and genotype or medication status as the independent variable. Pearson correlations were computed to analyze the relation between duration of illness and VDM. All analyses were computed using the SPSS package, version 17.0.

\section{Results}

The descriptive characteristics, genotype distribution and allele frequencies of the sample are displayed in table 1. The TCF4 variant was in Hardy-Weinberg equilibrium in the present study $(\mathrm{p}=0.068)$. As expected, the frequency of the $\mathrm{C}$ allele was only $6 \%$. Since the CC genotype of the rs 9960767 polymorphism was present in only 4 patients, subjects with either a CA or a CC genotype were combined and compared against subjects carrying the AA genotype in all subsequent analyses.

With regard to the demographic characteristics of the sample, no differences were found between TCF4 genotypes in any of the variables age $(F=0.349$; d.f. $=1 ; p=$ $0.555)$, gender $\left(\chi^{2}=0.027\right.$; d.f. $\left.=1 ; \mathrm{p}=0.870\right)$ and intelligence $(\mathrm{F}=0.023$; d.f. $=1 ; \mathrm{p}=0.881)$. The same was true for the clinical characteristics of the patient sample: age at onset, duration of illness, medication type and DSMIV subtype were not related to TCF4 genotype (table 2). To analyze the effect of differential drug treatment, we compared schizophrenia patients treated with at least 1 atypical antipsychotic $(\mathrm{n}=241)$ with those being treated with only conventional neuroleptics $(n=58)$. However, none of the memory parameters analyzed were affected by the type of drug treatment in our study (all p > 0.20). Correlation analyses indicated a small correlation of duration of illness with recognition $(r=0.123 ; p=0.016$; adjusted for age).

Next, we analyzed VDM performance as a function of the TCF4 genotypes. No significant associations between TCF4 genotype and immediate recall $(\mathrm{F}=1.25$; d.f. $=1$; $\mathrm{p}=0.264)$ and total learning $(\mathrm{F}=2.36 ; \mathrm{d} . \mathrm{f} .=1 ; \mathrm{p}=0.125)$ were found. A trend toward higher performance in CA/ $\mathrm{CC}$ genotype carriers in delayed recall emerged (AA genotype: $9.41 \pm 3.62$; CA/CC genotype: $10.24 \pm 3.27$; F = 2.93; d.f. $=1 ; \mathrm{p}=0.088$ ) (fig. 1). Moreover, in recognition, this genotype was significantly associated with better performance compared to carriers of the AA genotype (AA genotype: $13.06 \pm 2.20$; CA/CC genotype: $13.76 \pm 1.22$; $\mathrm{F}=3.90$; d.f. $=1 ; \mathrm{p}=0.049$ ) (fig. 1). When using age, gender, intelligence and duration of illness as covariates, this was a trend finding (AA genotype: $13.09 \pm 1.08$; CA/CC genotype: $13.66 \pm 2.90 ; \mathrm{F}=2.76$; d.f. $=1 ; \mathrm{p}=0.098$ ), while no effect for the remaining memory variables was found.

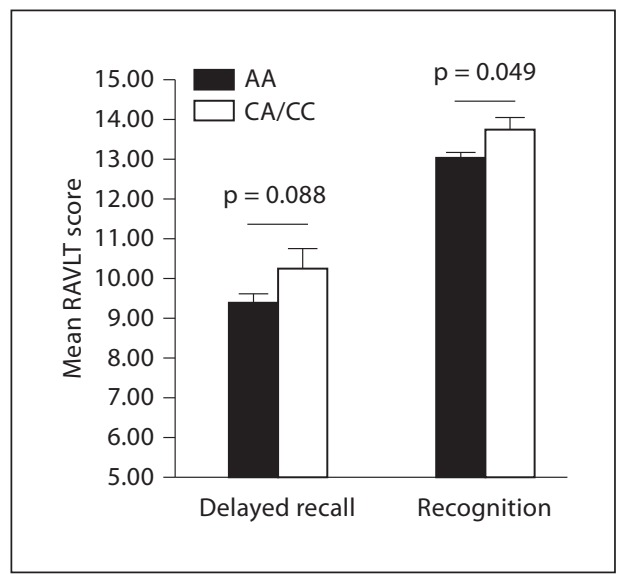

Fig. 1. VDM in schizophrenia patients. Means and SEM of RAVLT scores are displayed.

Table 1. Genotype information and demographic characteristics of schizophrenia patients $(\mathrm{n}=401)$

$\begin{array}{lc}\text { Age, years } & 37.8 \pm 10.9 \\ \text { Gender, \% male } & 58.1 \\ \text { IQ } & 105.2 \pm 17.7 \\ \text { CC/CA/AA, n } & 4 / 45 / 352 \\ \text { Allele A frequency } & 0.934 \\ \text { Allele C frequency } & 0.066\end{array}$

Age and IQ are shown as means $\pm \mathrm{SD}$. IQ = Intelligence measured by MWT-B or WAIS-R.

\section{Discussion}

This study investigated the novel schizophrenia candidate gene TCF4, which previously was reported to be associated with the disorder in a large GWAS [12]. Based on the study conducted by Stefánsson et al. [12] and on the extensive literature documenting highly replicable memory deficits in schizophrenia, we had hypothesized that schizophrenia subjects carrying the disease-associated $\mathrm{C}$ allele of the variant rs9960767 would show impaired verbal memory functioning. Contrary to our a priori assumption, patients with this allele performed significantly better with regard to recognition. Moreover, a trend toward a higher mean in recalled words after the 30-min delay was found in $\mathrm{C}$ allele carriers. There was no other statistical relationship between VDM deficits and TCF4 genotype. 
Table 2. Clinical characteristics of schizophrenia patients stratified for genotype

\begin{tabular}{llll}
\hline & AA & CA/CC & Statistics \\
\hline Age at onset, years $(\mathrm{n}=385)$ & $25.8 \pm 8.9$ & $24.4 \pm 7.9$ & $\mathrm{t}=0.985 ; \mathrm{p}=0.325$ \\
Duration of illness, years $(\mathrm{n}=385)$ & $12.1 \pm 9.6$ & $12.1 \pm 9.9$ & $\mathrm{t}=0.003 ; \mathrm{p}=0.997$ \\
Schizophrenia subtype $^{\mathrm{a}} \%(\mathrm{n}=394)$ & $74.0: 26.0$ & $68.8: 31.3$ & $\chi^{2}=0.592 ; \mathrm{p}=0.442$ \\
Type of medication $^{\mathrm{b}}, \%(\mathrm{n}=299)$ & $19.8: 80.2$ & $16.2: 83.8$ & $\chi^{2}=0.273 ; \mathrm{p}=0.601$ \\
\hline
\end{tabular}

Age and duration of illness are shown as means \pm SD. Different numbers are due to missing data.

${ }^{a}$ Ratio of paranoid subtype versus other subtypes.

${ }^{\mathrm{b}}$ Ratio of patients treated with only typical antipsychotics versus patients treated with any atypical antipsychotic.

The TCF4 gene has been reported to be involved in brain development [14]. Prior studies have shown a role of TCF4 in the Pitt-Hopkins syndrome [15], a severe neurodevelopmental disorder with serious physiological abnormalities [16-18]. Since a de novo translocation disrupting exon 4 of TCF 4 was recently seen in a girl with mental retardation, TCF4 is also implicated in milder forms of cognitive disabilities compared to the Pitt-Hopkins syndrome [19]. We therefore investigated the potential role of this gene in neuropsychological dysfunctions in schizophrenia. The studies on the Pitt-Hopkins syndrome and that conducted by Kalscheuer et al. [19], both relating the TCF4 gene to mental disabilities, also indicate an influence of TCF4 on general intellectual functioning. However, in our study the TCF4 genotype did not affect intelligence in subjects with schizophrenia. Although we had to discard our main hypothesis regarding a link between impaired memory functioning and the $\mathrm{C}$ allele of the rs9960767, the results of the present investigation suggest a role of TCF4 in the development of memory-related neuronal structures.

There are several areas of the central nervous system involved in memory functioning. Since studies on patients with lesions of the prefrontal cortex (PFC) and the medial-temporal lobe (MTL) found impaired memory in these patients, numerous studies have investigated the role of the PFC and MTL in memory function $[27,28]$. Studies linking memory performance with neuronal volume and activation in schizophrenia are in line with the findings in healthy subjects. With regard to MTL, a well-documented reduction in hippocampus volume in schizophrenia patients is evident [29-31]. These abnormal findings from volumetric studies are further encouraged by fMRI studies investigating regional activation during memory tasks. Heckers et al. [32,33] reported a series of studies linking reduced activity in the hippocampus and impaired verbal memory function in schizophrenia patients. A recent metaanalysis including $18 \mathrm{im}-$ aging studies replicated the finding of reduced activation of the hippocampus during encoding and retrieval in schizophrenia [20]. The PFC has been related to memory deficits in schizophrenia following the observation that most schizophrenia patients do not utilize semantic coding strategies during encoding. In line with this, it has been reported that VDM deficits in schizophrenia patients attenuate after a systematic training in semantic coding strategies, or due to a different presentation of the material $[34,35]$. In their metaanalysis, Achim and Lepage [20], among others, found a consistently reduced activation of the left inferior PFC in different learning and memory tasks in schizophrenia patients compared to healthy control subjects. Other studies including those by Heckers et al. [32, 33] mentioned above found elevated activity patterns in the PFC during encoding and retrieval [36]. Of particular interest for the present study are investigations reporting hippocampal data from unaffected high-risk subjects and relatives of schizophrenics. In high-risk subjects, a reduced hippocampal volume has been demonstrated [37]. Seidman et al. [38] also found abnormally reduced hippocampi in unaffected first-degree relatives of schizophrenia patients. Moreover, left hippocampal volumes in relatives were positively related to VDM deficits found in comparison to healthy control subjects [21]. These results stress a genetically determined abnormal hippocampus volume in schizophrenia patients and their relatives, and thus emphasize a developmental view of the disorder with VDM deficits inherited within families. Summing up the evidence on neuronal activation and memory in schizophrenia, a well-replicated insufficiency in the recruitment of the MTL and ab- 
normal activation of the PFC have been reported during memory task performance in schizophrenia patients and their unaffected relatives. These results prompted us to assume a potential link between TCF4 and memory-related structures which we indirectly tested using VDM data from schizophrenia patients. However, we were not able to analyze structural hippocampal data in our study. Further research should address the relation of TCF4 variation to hippocampal volume or activation.

VDM constitutes an excellent endophenotype of schizophrenia which has already provided noticeable results in the search for candidate genes in the last years. For instance, the met ${ }^{66}$ allele of the brain-derived neurotrophic factor 1 gene has been repeatedly associated with memory deficits in patients suffering from schizophrenia [39-41] and their unaffected first-degree relatives [42]. Moreover, VDM deficits precede acute psychotic episodes [43] and tend to be stable even after antipsychotic treatment with second generation neuroleptics [5]. In our study, this was supported by the finding that atypical drug treatment was not superior to conventional antipsychotics in terms of memory functioning. The high stability of VDM deficits was underlined by the fact that duration of illness did not show any relation to verbal learning or retrieval, while only a small positive correlation of duration of illness with recognition memory was obtained in schizophrenia patients. This is in line with a metaanalysis conducted by Aleman et al. [7], who did not find any relation of duration of illness to memory performance as well.

In conclusion, the elevated risk for developing schizophrenia conferred by the C allele of TCF4 rs9960767 is apparently not mediated by VDM deficits. Nevertheless, memory functioning is altered by the TCF4 genotype, suggesting a role of this variant in the development of memory-related brain structures.

\section{Acknowledgments}

We thank V. Guttenthaler, A. Petruschke and C. Hanses for their expert technical assistance. The authors thank all clinicians, psychiatrists, psychologists and study nurses involved in the study.

This study was part of the German Research Network on Schizophrenia and was funded by the German Federal Ministry for Education and Research BMBF (grants 01GI0501, 01GI0232, 01GI0234 and 01GV0907, and NGFN+ MooDs PNM01GS08146-3) and by the 7th framework programme of the European Union (ADAMS project, HEALTH-F4-2009-242257).

\section{References}

$>1$ Rössler W, Salize HJ, van Os J, RiecherRössler A: Size of burden of schizophrenia and psychotic disorders. Eur Neuropsychopharmacol 2005; 15:399-409.

-2 Sullivan PF, Kendler KS, Neale MC: Schizophrenia as a complex trait: evidence from a meta-analysis of twin studies. Arch Gen Psychiatry 2003;60:1187-1192.

$>$ Gottesman II, Gould TD: The endophenotype concept in psychiatry: etymology and strategic intentions. Am J Psychiatry 2003; 160:636-645.

4 Leboyer M, Bellivier F, Nosten-Bertrand M, Jouvent R, Pauls D, Mallet J: Psychiatric genetics: search for phenotypes. Trends Neurosci 1998;21:102-105.

5 Gur RE, Calkins ME, Gur RC, Horan WP, Nuechterlein KH, Seidman LJ, Stone WS: The consortium on the genetics of schizophrenia: neurocognitive endophenotypes. Schizophr Bull 2007;33:49-68.

6 Heinrichs RW, Zakzanis KK: Neurocognitive deficit in schizophrenia: a quantitative review of the evidence. Neuropsychology 1998; 12:426-445.
7 Aleman A, Hijman R, de Haan EH, Kahn RS: Memory impairment in schizophrenia: a meta-analysis. Am J Psychiatry 1999;156: 1358-1366.

8 Faraone SV, Seidman LJ, Kremen WS, Toomey R, Pepple JR, Tsuang MT: Neuropsychologic functioning among the nonpsychotic relatives of schizophrenic patients: the effect of genetic loading. Biol Psychiatry 2000;48: 120-126.

-9 Sitskoorn MM, Aleman A, Ebisch SJ, Appels MC, Kahn RS: Cognitive deficits in relatives of patients with schizophrenia: a meta-analysis. Schizophr Res 2004;71:285-295.

10 Snitz BE, Macdonald AW 3rd, Carter CS: Cognitive deficits in unaffected first-degree relatives of schizophrenia patients: a metaanalytic review of putative endophenotypes. Schizophr Bull 2006;32:179-194.

11 Whyte MC, McIntosh AM, Johnstone EC, Lawrie SM: Declarative memory in unaffected adult relatives of patients with schizophrenia: a systematic review and meta-analysis. Schizophr Res 2005;78:13-26.
12 Stefánsson H, Ophoff RA, Steinberg S, Andreassen OA, Cichon S, Rujescu D, Werge T, Pietiläinen OP, Mors O, Mortensen PB, Sigurðsson E, Gustafsson O, Nyegaard M, Tuulio-Henriksson A, Ingason A, Hansen T, Suvisaari J, Lönnqvist J, Paunio T, Børglum AD, Hartmann A, Fink-Jensen A, Nordentoft M, Hougaard D, Norgaard-Pedersen B, Böttcher Y, Olesen J, Breuer R, Möller HJ, Giegling I, Rasmussen HB, Timm S, Mattheisen M, Bitter I, Réthelyi JM, Magnúsdóttir BB, Sigmundsson T, Ólason P, Masson G, Gulcher JR, Haraldsson M, Fossdal R, Porgeirsson TE, Porsteinsdóttir U, Ruggeri M, Tosato S, Franke B, Strengman E, Kiemeney LA, Melle I, Djurovic S, Abramova L, Kaleda V, Sanjuan J, de Frutos R, Bramon E, Vassos E, Fraser G, Ettinger U, Picchioni M, Walker N, Toulopoulou T, Need AC, Ge D, Yoon JL, Shianna KV, Freimer NB, Cantor RM, Murray R, Kong A, Golimbet V, Carracedo A, Arango C, Costas J, Jönsson EG, Terenius L, Agartz I, Pétursson H, Nöthen MM, Rietschel M, Matthews PM, Muglia P, Peltonen L, St Clair D, Goldstein DB, Stefánsson $\mathrm{K}$, Collier DA: Common variants conferring risk of schizophrenia. Nature 2009;460:744747. 
13 Lewis CM, Levinson DF, Wise LH, DeLisi LE, Straub RE, Hovatta I, Williams NM, Schwab SG, Pulver AE, Faraone SV, Brzustowicz LM, Kaufmann CA, Garver DL, Gurling HM, Lindholm E, Coon H, Moises HW, Byerley W, Shaw SH, Mesen A, Sherrington R, O’Neill FA, Walsh D, Kendler KS, Ekelund J, Paunio T, Lönnqvist J, Peltonen L, O’Donovan MC, Owen MJ, Wildenauer DB, Maier W, Nestadt G, Blouin JL, Antonarakis SE, Mowry BJ, Silverman JM, Crowe RR, Cloninger CR, Tsuang MT, Malaspina D, Harkavy-Friedman JM, Svrakic DM, Bassett AS, Holcomb J, Kalsi G, McQuillin A, Brynjólfsson J, Sigmundsson T, Pétursson $\mathrm{H}$, Jazin E, Zoëga T, Helgason T: Genome scan meta-analysis of schizophrenia and bipolar disorder. Part 2. Schizophrenia. Am J Hum Genet 2003;73:34-48.

-14 Flora A, Garcia JJ, Thaller C, Zoghbi HY: The E-protein Tcf4 interacts with Math1 to regulate differentiation of a specific subset of neuronal progenitors. Proc Natl Acad Sci USA 2007;104:15382-15387.

15 Pitt D, Hopkins I: A syndrome of mental retardation, wide mouth and intermittent overbreathing. Aust Paediatr J 1978;14:182184.

16 Rosenfeld JA, Leppig K, Ballif BC, Thiese H, Erdie-Lalena C, Bawle E, Sastry S, Spence JE, Bandholz A, Surti U, Zonana J, Keller K, Meschino W, Bejjani BA, Torchia BS, Shaffer LG: Genotype-phenotype analysis of TCF4 mutations causing Pitt-Hopkins syndrome shows increased seizure activity with missense mutations. Genet Med 2009;11:797805.

17 de Pontual L, Mathieu Y, Golzio C, Rio M, Malan V, Boddaert N, Soufflet C, Picard C, Durandy A, Dobbie A, Heron D, Isidor B, Motte J, Newburry-Ecob R, Pasquier L, Tardieu M, Viot G, Jaubert F, Munnich A, Colleaux L, Vekemans M, Etchevers H, Lyonnet $\mathrm{S}$, Amiel J: Mutational, functional, and expression studies of the TCF4 gene in PittHopkins syndrome. Hum Mutat 2009;30: 669-676.

-18 Zweier C, Peippo MM, Hoyer J, Sousa S, Bottani A, Clayton-Smith J, Reardon W, Saraiva J, Cabral A, Gohring I, Devriendt K, de Ravel T, Bijlsma EK, Hennekam RC, Orrico A, Cohen M, Dreweke A, Reis A, Nurnberg P, Rauch A: Haploinsufficiency of TCF4 causes syndromal mental retardation with intermittent hyperventilation (Pitt-Hopkins syndrome). Am J Hum Genet 2007;80:994-1001.

-19 Kalscheuer VM, Feenstra I, van Ravenswaaij-Arts CM, Smeets DF, Menzel C, Ullmann R, Musante L, Ropers HH: Disruption of the TCF4 gene in a girl with mental retardation but without the classical Pitt-Hopkins syndrome. Am J Med Genet A 2008; 146A:2053-2059.
20 Achim AM, Lepage M: Episodic memoryrelated activation in schizophrenia: metaanalysis. Br J Psychiatry 2005;187:500-509.

21 Seidman LJ, Faraone SV, Goldstein JM, Kremen WS, Horton NJ, Makris N, Toomey R, Kennedy D, Caviness VS, Tsuang MT: Left hippocampal volume as a vulnerability indicator for schizophrenia: a magnetic resonance imaging morphometric study of nonpsychotic first-degree relatives. Arch Gen Psychiatry 2002;59:839-849.

22 American Psychiatric Association: Diagnostic and Statistical Manual of Mental Disorders, ed 4. Washington, American Psychiatric Association, 1994.

23 World Health Organization: International Classification of Disease, rev 10. Geneva, World Health Organization, 1992.

24 Helmstaedter C, Lendt M, Lux S: VLMT Verbaler Lern- und Merkfähigkeitstest. Göttingen, Beltz, 2001

25 Lehrl S, Merz J, Burkhard G, Fischer S Mehrfachwahl-Wortschatz-Intelligenztest. Göttingen, Hogrefe, 1999.

26 Tewes U: Hamburg-Wechsler-Intelligenztest für Erwachsene, Revision (HAWIE-R). Göttingen, Hogrefe, 1991.

27 Blumenfeld RS, Ranganath C: Prefrontal cortex and long-term memory encoding: an integrative review of findings from neuropsychology and neuroimaging. Neuroscientist 2007;13:280-291.

28 Spaniol J, Davidson PS, Kim AS, Han H, Moscovitch M, Grady CL: Event-related fMRI studies of episodic encoding and retrieval: meta-analyses using activation likelihood estimation. Neuropsychologia 2009; 47:1765-1779.

29 Bogerts B, Falkai P, Greve B: Evidence of reduced temporolimbic structure volumes in schizophrenia. Arch Gen Psychiatry 1991; 48:956-958.

30 Wright IC, Rabe-Hesketh S, Woodruff PW, David AS, Murray RM, Bullmore ET: Metaanalysis of regional brain volumes in schizophrenia. Am J Psychiatry 2000;157:16-25.

31 Falkai P, Bogerts B: Cell loss in the hippocampus of schizophrenics. Eur Arch Psychiatry Neurol Sci 1986;236:154-161.

32 Heckers S, Goff D, Schacter DL, Savage CR, Fischman AJ, Alpert NM, Rauch SL: Functional imaging of memory retrieval in deficit vs nondeficit schizophrenia. Arch Gen Psychiatry 1999;56:1117-1123.
33 Heckers S, Rauch SL, Goff D, Savage CR, Schacter DL, Fischman AJ, Alpert NM: Impaired recruitment of the hippocampus during conscious recollection in schizophrenia. Nat Neurosci 1998;1:318-323.

34 McClain L: Encoding and retrieval in schizophrenics' free recall. J Nerv Ment Dis 1983; 171:471-479.

35 Ragland JD, Moelter ST, McGrath C, Hill SK, Gur RE, Bilker WB, Siegel SJ, Gur RC: Levels-of-processing effect on word recognition in schizophrenia. Biol Psychiatry 2003;54: 1154-1161.

36 Heckers S: Neuroimaging studies of the hippocampus in schizophrenia. Hippocampus 2001;11:520-528.

-37 Lawrie SM, Whalley H, Kestelman JN, Abukmeil SS, Byrne M, Hodges A, Rimmington JE, Best JJ, Owens DG, Johnstone EC: Magnetic resonance imaging of brain in people at high risk of developing schizophrenia. Lancet 1999;353:30-33.

$>38$ Seidman LJ, Faraone SV, Goldstein JM, Goodman JM, Kremen WS, Toomey R, Tourville J, Kennedy D, Makris N, Caviness VS, Tsuang MT: Thalamic and amygdalahippocampal volume reductions in first-degree relatives of patients with schizophrenia: an MRI-based morphometric analysis. Biol Psychiatry 1999;46:941-954.

>39 Egan MF, Kojima M, Callicott JH, Goldberg TE, Kolachana BS, Bertolino A, Zaitsev E, Gold B, Goldman D, Dean M, Lu B, Weinberger DR: The BDNF val66met polymorphism affects activity-dependent secretion of BDNF and human memory and hippocampal function. Cell 2003;112:257-269.

40 Ho BC, Milev P, O’Leary DS, Librant A, Andreasen NC, Wassink TH: Cognitive and magnetic resonance imaging brain morphometric correlates of brain-derived neurotrophic factor Val66Met gene polymorphism in patients with schizophrenia and healthy volunteers. Arch Gen Psychiatry 2006;63: 731-740.

41 Tan YL, Zhou DF, Cao LY, Zou YZ, Wu GY, Zhang XY: Effect of the BDNF Val66Met genotype on episodic memory in schizophrenia. Schizophr Res 2005;77:355-356.

42 Dempster E, Toulopoulou T, McDonald C, Bramon E, Walshe M, Filbey F, Wickham H, Sham PC, Murray RM, Collier DA: Association between BDNF val66met genotype and episodic memory. Am J Med Genet B Neuropsychiatr Genet 2005;134B:73-75.

$\checkmark 43$ Saykin AJ, Shtasel DL, Gur RE, Kester DB, Mozley LH, Stafiniak P, Gur RC: Neuropsychological deficits in neuroleptic naive patients with first-episode schizophrenia. Arch Gen Psychiatry 1994;51:124-131. 